\title{
Production and investigating the effect of Echium amoenum Fisch- 8Me (part of stem and leaf, wastes) extract as green and cheap corrosion inhibitor on St37 steel in $3.5 \mathrm{wt} \% \mathrm{NaCl}$ corrosive medium
}

\section{Bahare Ghanaati}

Shahid Bahonar University of Kerman

Ahmad Irannejad ( $\sim$ irannejhad@uk.ac.ir)

Shahid Bahonar University of Kerman https://orcid.org/0000-0001-7153-3443

\section{Fateme Baghaei raveri}

Shahid Bahonar University of Kerman

\section{Research Article}

Keywords: Green corrosion inhibitor, Echium amoenum Fisch- 8Me (part of stem and leaf, wastes) Extract, St37 Steel, $\mathrm{NaCl}$ corrosive medium

Posted Date: January 20th, 2022

DOI: https://doi.org/10.21203/rs.3.rs-1162345/v1

License: (9) This work is licensed under a Creative Commons Attribution 4.0 International License. Read Full License 


\section{Abstract}

The purpose of this study was to produce a green inhibitor from Echium amoenum Fisch-8Me plant wastes. The stems and leaves of this plant are a source of active compounds that can act as active sites for the adsorption of steel inhibitory molecules. First, the plant extract extracted using the maceration method. The polarization, EIS, FT-IR \& SEM tests performed. Electrochemical studies showed that this material, as a mixed inhibitor was reduced the corrosion rate by absorbing the surface of the metal and blocking active points. The highest inhibition efficiency in the corrosive environment of $3.5 \mathrm{wt} \% \mathrm{NaCl}$ in concentration 800 (ppm) Echium amoenum Fisch- 8Me (part of stem and leaf, wastes) extract was $92.2 \%$. This extract created a protective layer on the steel surface. Therefore; it can be said that the combination of several parts of the plant itself, such as (part of stem and leaf, wastes), Echium amoenum Fisch-8Me has a significant effect on increasing the inhibitory efficiency of the extract and the most beneficial and effective compounds in inhibition have been taken. It is introduced as a new green, environmentally friendly and cheap corrosion inhibitor on St37 steel in $3.5 \mathrm{wt} \% \mathrm{NaCl}$ corrosive medium.

\section{Novelty Statement}

The need to do this is to save the environment from pollutants of chemical and toxic inhibitors, to reduce environmental catastrophes by using efficient, inexpensive, affordable and environmentally friendly green inhibitors. Plants are an enormous source of natural compounds and by extracting these compounds, they can be used as a green corrosion inhibitor. In this research, part of the stem and leaves, plant wastes have been used. With the implementation of this research, plant waste will no longer be seen as a useless waste, but will become a valuable treasure. Progress over previous work is the use of a combination of several parts of the plant and had a significant effect on increasing the inhibitory efficiency of the extract.

\section{Introduction}

Corrosion inhibitors have been used since the 19th century. One of the easiest ways to protect against corrosion is to use inhibitors, which is one of the most popular ways to control corrosion of metals [1-4].

Chemical inhibitors fall into two categories: synthetic organic corrosion inhibitors and traditional inorganic corrosion inhibitors [5].

These chemical inhibitors have caused many environmental problems. Chromate, for example, is one of the most widely used chemical inhibitors due to the presence of the toxic metal $\mathrm{Cr}$, which is carcinogenic and pollutes the environment $[6,7]$.

The most effective inhibitors are heterocyclic and aliphatic compounds containing heteroatoms such as $\mathrm{P}, \mathrm{S}, \mathrm{N}$, and $\mathrm{O}$ in molecular structures. Nowadays, the replacement of chemical corrosion inhibitors with natural inhibitors has been considered by researchers for the mentioned reasons [8-10]. Green inhibitors are cheap, harmless and environmentally friendly, and easily found in abundance in nature. Different sources of environmentally friendly natural corrosion inhibitors are divided into two categories. 
First category: Inorganic green corrosion inhibitor. For example Rare earth elements, etc.

Second category: Organic green corrosion inhibitor. For example Plants, Drugs, Amino acids, Surfactants, Biopolymers, lonic liquids, etc.

Plants in this category are extracted and used in two forms: Extracts and Oils [5]

In this study, the aim was to produce green inhibitor from plant wastes. One of the researches in this field is the research report of Ali Dehghani et al. To prepare a green inhibitor by using the extract of Chinese gooseberry fruit shell, which is a waste material of Chinese gooseberry [11].

In this regard, we can refer to another report in 2020 by Liu et al. from Platanus acerifolia leaves (dried and discarded leaves (wastes) of this plant on the ground). The newest and best way to be economical and cheap, without harm to health and the environment, is to use a green deterrent. Using plant wastes as a green deterrent and finding the best effective compounds in different plant species is the best way to prevent corrosion of metals $[12,13]$.

To date, much research on green inhibitors, Such as Rosa damascene flower [14], Balsam Fir [15], Cinnamon [16], Garlic [17], Olive leaf [18], Kleinia grandiflora leaf extract [19], Xylopia ferruginea extract [20], Lavandula mairei [21], Bassia muricata [22], Robinia pseudoacacia Leaves [23], Coconut Leaf [24], Pineapple [25], Kiwi [26], Peach Pomace Extract [27], Idesia polycarpa Maxim fruits [28], Lilium brownii leaves [29], Red Algae Halopitys Incurvus [30], Prosopis farcta [31], Nutmeg oil [32], Elaeis guineensis Jacq [33], Peganum harmala seed [34], Allium cepa L [35], Henna [36], Three imidazole ionic liquids [37], Ionic liquids derived from a-amino acid ester salts [38], Locust Bean Gum [39], Juglans regia green fruit shell [40], Jujube shell [41], Neem [42], etc has been done. According to these reports, the ability to prevent corrosion has been proven in some spices, fruits, plants, flowers, oils, gums, plant seeds, and ionic liquids.

Today, to choose the suitable corrosion inhibitor, several important factors must be considered, such as containment efficiency, cost, availability, and environmental effects. It is important to note that many green inhibitors are not fully available in nature or are expensive, which is not cost-effective [11].

Considering these factors, in the present study, the use of Echium amoenum Fisch- 8Me (part of stem and leaf, wastes) extract has been considered as a green and environmentally friendly corrosion inhibitor that is found in abundance in nature and is not a problem to find. It is easily accessible and can be provided at a low cost, so it is cost-effective.

Echium amoenum Fisch- 8Me is one of the famous medicinal plants, Which has been used extensively in traditional medicine since The distant past. There are different genera of this plant in Iran. In this research part of stem and leaf (wastes) of this useful plant has been used.

In this study, the inhibition activity of the inhibitor was studied by EIS and potentiodynamic polarization tests. The composition of Echium amoenum Fisch- $8 \mathrm{Me}$ (part of stem and leaf, wastes) extract was 
studied by FT-IR analysis. The surface quality of St37 samples was analyzed by SEM before and after adding the inhibitor to the corrosive medium.

\section{Echium amoenum Fisch- 8Me (part of stem and leaf, wastes) extract preparation}

This plant contains small amounts of pyrrolizidine alkaloids, fatty acids (9.1\%), silicic acid, potassium, calcium, potassium nitrate, Acids (Acetic, lactic, and malic), Cyanogens.

So far, we are familiar with the compounds of Echium amoenum Fisch- 8Me. It has been observed what beneficial compounds are present in this plant species, so it is a correct choice as a green inhibitor in this research. In Fig. 1, you can see the image of the tested dried Echium amoenum Fisch-8Me (part of stem and leaf, wastes).

Preparation of Echium amoenum Fisch-8Me extract (part of stem and leaf, wastes): After preparing Echium amoenum Fisch-8Me (part of stem and leaf, wastes) and drying it in air, powder the plant Crush and separate 50 grams from powder using a digital balance and extract Echium amoenum Fisch-8Me (part of stem and leaf, wastes) using distilled water, acetone solvent, mixer, magnet, and filter paper and with using Heated mechanical stirrer extraction machine. This process is also called the traditional method of maceration, which is a cheap and optimal way to extract.

The extract of Echium amoenum Fisch-8Me (part of stem and leaf, wastes) is stored at low temperature until final use and testing.

\section{Methods}

\section{Sample preparation}

First, the St37 steel sheet was cut using a laser cutting machine in the dimensions of $1 \times 1 \mathrm{~cm}^{2}$, and then a $10 \mathrm{~cm}$ copper wire was connected to the St37 steel sheet using a soldering machine, and the samples were mounted using a hot mounting machine.

Samples were first sanded according to ASTM B25 standard with 400, 600, 800, 1200, and 2500 sandpaper, respectively. After sanding with coarse to soft sandpaper, the samples' surface was smoothed and polished and finally, the samples were degreased and washed with distilled water.

\section{Characterization}

\section{Potentiodynamic polarization test}

An EG\&G Potentiostat / Galvanostat Model 263A was used to perform these experiments. All electrochemical tests were executed in a three-electrode system, including St37 steel electrode (working electrode), platinum electrode (auxiliary electrode), and $\mathrm{Ag} / \mathrm{AgCl}$ (reference electrode). The experiments 
were performed under Potentiodynamic conditions, in the range of $-0.25 v$ to $+0.25 v$ relative to the open circuit potential and under a potential scan rate of $1 \mathrm{mV} \mathrm{s}{ }^{-1}$. All experiments were performed at room temperature, and the temperature parameter was considered constant. Polarization tests were performed according to the ASTM G61 standard. To check the correct corrosion, the effective surface of the samples was cleaned of any surface contamination before the test.

To make the electrolyte solution, $100 \mathrm{ml}$ of $3.5 \mathrm{wt} \% \mathrm{NaCl}$ was prepared. Concentrations of $0,400,600$, 800 ppm from Echium amoenum Fisch- 8Me (part of stem and leaf, wastes) extract were added to the solution separately. The electrode (St37 steel) is immersed in the electrolyte solution for one hour before each test to reach a stable state.

\section{EIS (Electrochemical Impedance Spectroscopy)}

Impedance studies were reviewed by EG\&G model 1025 equipped with Power Suite software. Also, the ZSimpWin software was used for the analysis of impedance data. Here, like the polarization test, the same electrodes were used. Due to the $\mathrm{OCP}$, the frequency range of $0.01 \mathrm{~Hz}$ to $100 \mathrm{kHz}$ and the oscillation amplitude of $10 \mathrm{mV}$ were selected. Electrochemical impedance tests were performed according to the ASTM G106 standard. At each stage after the end of the trial, the samples were sanded again and prepared for the next test.

\section{FT-IR (Fourier Transform Infrared Spectroscopy)}

One of the most widely used methods in the qualitative identification of different molecules is to determine the molecular structure of different species (especially organic species) and to identify the functional groups present in the structure of a species. The first and most widely used type is Fourier transform or FT-IR device that can analyze the entire spectral range using an interferometer system simultaneously shine on the sample. This spectroscopy method can be used for solids, liquids as well as gases, each of which requires different preparation steps for the sample and the use of its equipment. The infrared spectroscopy method has a wide range of applications in various fields, mostly qualitative and comparative.

Solid samples were used in this project, so the pelleting process is required for preparation. Mix a tiny amount of the solid sample (about one milligram or less) that is wholly powdered in a ratio of 1 to 100 with $\mathrm{KBr}$ completely dry, and then pour some of them into a particular metal mold and Press with a hydraulic press device ( 5 to 8 tons per square centimeter) to obtain a transparent tablet. 27 Tensor device was used to perform this test. From the wavelength of 400 to $4000 \mathrm{~cm}^{-1}$ was performed by the $\mathrm{KBr}$ disk method on the sample. Scan resolution was $4 \mathrm{~cm}^{-1}$, and scan rate was $16 \mathrm{~cm} / \mathrm{min}$.

\section{SEM (Scanning Electron Microscopy)}


To study and microstructural analysis of the samples, a Cam Scan MV2300 model scanning electron microscope equipped with EDS analysis was used. Twenty kV voltage was used to study the morphology of the samples' surface by the SEM machine. The samples were washed with distilled water before being placed in the apparatus.

\section{Results And Discussion}

\section{Potentiodynamic polarization test}

The polarization curves for the steel samples exposed to the solutions, including Echium amoenum Fisch- 8Me (part of stem and leaf, wastes) extract, are illustrated in Fig. 2. This figure shows the corrosion behavior of St37 steel for $3.5 \mathrm{wt} \% \mathrm{NaCl}$ medium and different concentrations of Echium amoenum Fisch$8 \mathrm{Me}$ (part of stem and leaf, wastes) extract. The blue curve shows the corrosive medium without inhibitor, and other curves show the different concentrations of the extract in the corrosive medium.

According to the polarization curves in Fig. 2, the following data can be obtained. These data were collected by Power Suite software, which can be used to analyze polarization curves. Electrochemical parameters related to the polarization test $\left(i_{\text {corr }}, E_{c o r r}\right.$, Tafel slopes $\left(\beta_{a}, \beta_{c}\right), \theta$, and \% IE) are shown in Table 1.

Table 1

Polarization data of St37 steel in $3.5 \mathrm{wt} \% \mathrm{NaCl}$ solution and containing Echium amoenum Fisch- 8Me (part of stem and leaf, wastes) extract with different concentrations

\begin{tabular}{|llllllll|}
\hline $\begin{array}{l}\text { concentration } \\
(\mathbf{p p m})\end{array}$ & $\mathrm{E}_{\text {corr }}(\mathrm{mV})$ & $\boldsymbol{\beta}_{\mathrm{c}}(\mathrm{mV} / \mathrm{dec})$ & $\boldsymbol{\beta}_{\mathrm{a}}(\mathrm{mV} / \mathrm{dec})$ & $\mathrm{I}_{\text {corr }}(\mu \mathrm{A})$ & $\mathrm{i}_{\text {corr }}\left(\mu \mathrm{A} / \mathrm{cm}^{2}\right)$ & $\boldsymbol{\theta}$ & $\mathrm{IE} \%$ \\
\hline 0 & -519.53 & 1949.02 & 115.27 & 22.95 & 22.95 & - & - \\
\hline 400 & -466.94 & 117.86 & 67.69 & 4.58 & 4.58 & 0.800 & 80.0 \\
\hline 600 & -511.05 & 105.43 & 58.25 & 2.28 & 2.28 & 0.901 & 90.1 \\
\hline 800 & -470.27 & 41.42 & 31.37 & 1.79 & 1.79 & 0.922 & 92.2 \\
\hline
\end{tabular}

Table 1 shows the polarization data of St37 steel in $3.5 \mathrm{wt} \% \mathrm{NaCl}$ solution containing Echium amoenum Fisch- $8 \mathrm{Me}$ (part of stem and leaf, wastes) extract with different concentrations. The effect of changing the extract's concentration on the electrochemical parameters related to the polarization test can be well observed. In Table 1, the corrosion potential parameter of steel is $\mathrm{E}_{\text {corr }}$ and the corrosion current density parameter is $i_{\text {corr }}$. The slopes of the cathode and anode lines are $\beta_{c}$ and $\beta_{a}$, respectively. The level of surface Coverage and inhibition efficiency is shown with $\theta$ and IE\%, calculated using Formula $(1)[22,43]$.

IE \% $=\theta \times 100=\left[1-\frac{i_{\text {corr (inh) }}}{i_{\text {corr (free })}}\right] \times 100$ 
That $\mathrm{i}_{\text {corr(free) }}$ and $\mathrm{i}_{\text {corr(inh) }}$ are corrosion current density in the inhibitor's absence and the inhibitor's presence, respectively.

Table 1 shows the parameters of corrosion reactions, which are derived from the extrapolation of Tafel lines. The data presented in this table show that add the extract in this corrosive medium affected both cathodic and anodic reactions and reduced corrosion current, cause slowed down the corrosion rate of St37 steel in the corrosive medium of $3.5 \mathrm{wt} \% \mathrm{NaCl}$. This means that the extract inhibits corrosion by preventing cathodic and anodic reactions, and it is observed that the Tafel Slope is reduced in both anodic and cathodic reactions. This is probably due to the coating of inhibitor adsorbed molecules on the surface, and the reach of corrosive ions into the surface of the steel is reduced. According to Table 1, the inhibition effect of this extract increased with increasing concentration.

The inhibitory effect of Echium amoenum Fisch- 8Me (part of stem and leaf, wastes) extract increased with increasing the concentration of the extract in the solution and reduced the corrosion current density $\left(\mathrm{i}_{\text {corr }}\right)$. Different concentrations of the extract should be tested to determine the optimal concentration for the inhibitor. The play in the role of Echium amoenum Fisch-8Me (part of stem and leaf, wastes) extract as a corrosion inhibitor for St37 steel in the corrosive medium of $3.5 \mathrm{wt} \% \mathrm{NaCl}$ is well seen. With increasing inhibitor concentration, inhibition efficiency increased. The maximum inhibitory efficiency is related to the concentration of 800 ppm, Echium amoenum Fisch- 8Me (part of stem and leaf, wastes) extract in the corrosive environment of $3.5 \mathrm{wt} \% \mathrm{NaCl}$ equal to $92.2 \%$.

The emission of electron density in inhibition molecules leads to the molecule's tendency to be adsorbed in both the anode and cathode regions. In this case, the electrochemical activities in both the anode and cathode regions are affected, and reactions are polarized. It can be claimed that the extract molecules adhere to the metal surface, thus blocking many of the active sites at that surface, leading to the increased amount of inhibition, as a result, prevents corrosion. Therefore, the tested extract can be considered as a mixed-type inhibitor [18, 31].

For a more detailed analysis, according to Table 1, The corrosion potential of steel in $3.5 \mathrm{wt} \% \mathrm{NaCl}$ solution without inhibitor was $-519 / 53(\mathrm{mV})$. In the presence of inhibitor at the concentration of $400 \mathrm{ppm}$ was equal to $-466 / 94(\mathrm{mV})$. So at potentials more positive than the corrosion potential in solution without inhibitor, we have a decrease in the flow's viscosity, in which case the inhibitor reduces the corrosion by adsorbing more on the anodic regions. However, the corrosion potential of steel in higher concentration containing inhibitor at $600 \mathrm{ppm}$ was equal to $-511.05(\mathrm{mV})$. There is a slight difference between the corrosion potential of steel in this concentration and the state without inhibitors. So the corrosion potential of steel with The addition of the inhibitor is not significantly affected, indicating the mixed behavior of green inhibitor.

\section{EIS (Electrochemical Impedance Spectroscopy)}

Figure 3-a shows Nyquist curves, Fig. 3-b shows Bode curves, and Fig. 3-c shows Bode Phase curves for the corrosion of St37 steel in the corrosive medium of $3.5 \mathrm{wt} \% \mathrm{NaCl}$ the presence of different 
concentrations of Echium amoenum Fisch-8Me (part of stem and leaf, wastes) extract in the electrochemical impedance test. The blue curve shows the corrosive medium without inhibitor, and other curves show the different concentrations of the extract in the corrosive medium.

\section{Impedance test equivalent circuit}

A corrosion process can be simulated with an electrical circuit because it is the nature of both electron transmissions. Therefore, to investigate the corrosion behavior, the experimental data were matched using ZSimpWin software. When modeling some processes, it is necessary to use a CPE in the imaginary part (capacity). When a capacity behavior cannot be satisfactorily demonstrated with a capacitor, which sometimes occurs in corrosion processes, a CPE is used instead of a capacitor.

With the use of this software, an equivalent circuit related to St37 steel impedance test data was prepared in the corrosive medium of $3.5 \mathrm{wt} \% \mathrm{NaCl}$ in the presence of different concentrations of Echium amoenum Fisch-8Me (part of stem and leaf, wastes) extract. Fig. 4 shows the $R(Q(R(Q R))$ circuit (the best equivalent circuit according to the experimental data). The electrochemical parameters obtained from the equivalent circuit of Fig. 4 are given in Table 2.

Table 2

Electrochemical spectroscopy results of St37 steel in $3.5 \mathrm{wt} \% \mathrm{NaCl}$ solution containing Echium amoenum Fisch- 8Me (part of stem and leaf, wastes) extract with different concentrations

\begin{tabular}{|c|c|c|c|c|c|c|c|c|}
\hline $\begin{array}{l}\text { concentration } \\
\text { ppm)) }\end{array}$ & $\begin{array}{l}\mathrm{R}_{\mathrm{s}} \\
(\Omega . \mathrm{cm})^{2}\end{array}$ & $\begin{array}{l}Y_{\mathrm{dl}}(\Omega \\
\left.. \mathrm{cm}^{-2} \cdot \mathrm{s}^{\mathrm{n}}\right)\end{array}$ & $\mathrm{n}_{\mathrm{dl}}$ & $\begin{array}{l}\mathrm{R}_{\mathrm{ct}} \\
(\Omega . \mathrm{cm})^{2}\end{array}$ & $\begin{array}{l}Y_{f}(\Omega \\
\left.. \mathrm{cm}^{-2} \cdot \mathrm{s}^{\mathrm{n}}\right)\end{array}$ & $n_{f}$ & $\begin{array}{l}R_{f} \\
(\Omega . c m)^{2}\end{array}$ & IE\% \\
\hline 0 & 7.711 & $1.419 p 10^{-3}$ & 0.8 & 8.615 & $6.502 p 10^{-3}$ & 0.8 & 437 & - \\
\hline 400 & 9.145 & $1.012 p 10^{-3}$ & 0.6 & 59.44 & $1.168 \rho 10^{-4}$ & 0.9 & 1275 & 85.51 \\
\hline 600 & 8.733 & $2.945 \rho 10^{-4}$ & 0.7 & 222 & $2.785 \rho 10^{-4}$ & 0.6 & 1938 & 96.12 \\
\hline 800 & 5.415 & $1.432 p 10^{-4}$ & 0.8 & 1268 & $1.477 \rho 10^{-3}$ & 0.8 & 2781 & 99.32 \\
\hline
\end{tabular}

To match the spectrum curve with the logic circuit model, Nonlinear regression is used. The number of adjustable parameters in this model is seven $\left(R_{s} \rrbracket Y_{d l} \rrbracket n_{d l} \rrbracket R_{c t} \rrbracket Y_{f} \rrbracket n_{f} \rrbracket R_{f}\right)$ Which is given in Table 2. The symbol $R$ indicates the resistance. In this table, $R_{s}$ is the solution resistance and, $R_{c t}$ is the charge transfer resistance, $R_{f}$ is the surface film resistance. In Fig. 4, $C P E_{d l}$ and $C P E_{f}$ also show the capacity of the double layer constant phase element and the constant phase element capacity of the surface film formed on the surface, respectively. To show it, two parameters, $\mathrm{Y}$ (admittance) and $\mathrm{n}$ (surface non-uniformity coefficient) are used. To calculate the inhibition efficiency using impedance curve information, Formula (2) was used $[22,44]$.

$I E \%=\theta \times 100=\left[1-\left(\frac{\left(R_{c t}^{0}\right)}{R_{c t}}\right)\right] 100$ 
That $\mathrm{R}_{\mathrm{ct}}{ }^{0}$ and $\mathrm{R}_{\mathrm{ct}}$ show the charge transfer resistance in the inhibitor's absence and the inhibitor's presence, respectively. The electrochemical parameters obtained from the equivalent circuit of Fig. 4 are given in Table 2.

From the Nyquist curves (impedance response of St37 steel electrode) Fig. 3-a with and without Echium amoenum Fisch- 8Me (part of stem and leaf, wastes) extract in the corrosive environment of $3.5 \mathrm{wt} \%$ $\mathrm{NaCl}$ is determined that by adding Inhibitor to the solution, the diameter of the semicircles increases, which indicates an increase in the surface resistance to corrosion and a decrease in the corrosion rate due to the formation of a protective film on the surface of the steel electrode.

According to Fig. 3-b and Fig. 3-c, in Bode and Bode Phase curves in terms of frequency, a sample with a high value of $Z$ (impedance) at low frequencies means a significant increase in corrosion resistance. On the vertical axis of the Bode curve, it can be seen that increasing the concentration of inhibition extract resulted in the rate of corrosion resistance has increased and had excellent resistance. The surface nonuniformity coefficient ( $n$ ), as shown in Table 2 of the parameters extracted from the Z-sime software, is almost $n=0.8$, which indicates the specific behavior, and the choice of $\mathrm{Q}$ or CPE (constant phase element) in the equivalent circuit is correct. The reason for using constant phase elements in this circuit is to ensure that the circuit's capacitance matches the data obtained from the impedance test. The obtained impedance results can be analyzed based on the equivalent circuit of Fig. 4. The logic circuit corresponding to the impedance results of the inhibition Echium amoenum Fisch-8Me (part of stem and leaf, wastes) extract shows the electrode with incomplete coating. According to Table 2 , it can be seen that at the optimal concentration of $800 \mathrm{ppm}$, the values of $R_{c t}$ and $R_{f}$ have increased. The capacitance values for the constant phase elements have been almost declining. A significant increase in charge transfer resistance indicates that more inhibition molecules are adsorbed to the steel surface, reducing the active sites present on the surface for the metal dissolution reaction. The maximum inhibition efficiency for the concentration of 800 ppm Echium amoenum Fisch- 8Me (part of stem and leaf, wastes) extract in the corrosive medium of $3.5 \mathrm{wt} \% \mathrm{NaCl}$ is equal $99.32 \%$. This finding is very consistent with the results of the polarization test. These results demonstrate the effective corrosion inhibition ability of Echium amoenum Fisch- 8Me (part of stem and leaf, wastes) extract in the corrosive environment of 3.5 wt\% $\mathrm{NaCl}$.

\section{FT-IR (Fourier Transform Infrared Spectroscopy) test}

Results from infrared spectroscopy for Echium amoenum Fisch- 8Me (part of stem and leaf, wastes) extract and surface film of St37 steel sample immersed for 24 hours in $3.5 \mathrm{wt} \% \mathrm{NaCl}$ solution containing one gr/l of Echium amoenum Fisch- 8Me (part of stem and leaf, wastes) extract is given in Fig. 5.

Organic inhibitors are mostly of the mixed type. They are usually adsorbed on the metal surface due to the presence of polar groups such as $\mathrm{CO}, \mathrm{CS}, \mathrm{CN}$, and $\mathrm{CP}$ in the molecules of these inhibitors, as well as the presence of free electrons in the $\mathrm{S}, \mathrm{O}, \mathrm{N}$, and $\mathrm{P}$ atoms. They provide a protective coating on the metal surface. 
In the study of FT-IR results, by observing the images and peaks taken from this experiment, the existence of these polar groups in the worked green inhibitor is confirmed. The FT-IR spectrum of dried Echium amoenum Fisch- 8Me (part of stem and leaf, wastes) extract is shown in Fig. 5-a. The broad peak in wavenumber $3409.96 \mathrm{~cm}^{-1}$ is related to the group's vibrations $(\mathrm{O}-\mathrm{H})$ and $(\mathrm{N}-\mathrm{H})$. The presence of peak $2942.30 \mathrm{~cm}^{-1}$ is related to group vibrations (C-H). The peak $1595.22 \mathrm{~cm}^{-1}$ is related to the asymmetric tensile vibrations of the group $(C=C)$. The peak $1143.96 \mathrm{~cm}^{-1}$ is related to the groups' vibrations $(C-0)$, (C$\mathrm{N})$, and $(\mathrm{S}=0)$. The peak $1014.71 \mathrm{~cm}^{-1}$ is related to the groups' vibrations $(\mathrm{C}-\mathrm{O})$ and $(\mathrm{C}-\mathrm{N})$. Peak 779.35 $\mathrm{cm}^{-1}$ is related to group vibrations $(\mathrm{C}-\mathrm{H})$, and peak $676.52 \mathrm{~cm}^{-1}$ is related to aromatic rings.

However, in the FT-IR spectrum, the formed film on the surface of St37 steel after one day of immersion in $3.5 \mathrm{wt} \% \mathrm{NaCl}$ medium containing one $\mathrm{g} / \mathrm{l}$ of Echium amoenum Fisch- 8Me (part of stem and leaf, wastes) extract is shown in Fig. 5-b. It is observed that the peak resulting from vibrations $(\mathrm{O}-\mathrm{H})$ and $(\mathrm{N}-\mathrm{H})$ has increased from 3409.96 to $3423.98 \mathrm{~cm}^{-1}$. The peak corresponding to group vibrations $(\mathrm{C}-\mathrm{H})$ has been transferred from 2942.30 to $2926.45 \mathrm{~cm}^{-1}$. The peak $2705.94 \mathrm{~cm}^{-1}$ is a new peak, which corresponds to the group's vibrations (C-H). The peak $2347.76 \mathrm{~cm}^{-1}$ is a new peak, which corresponds to the group's vibrations $(C \equiv N)$. The peak from vibrations $(C=C)$ has increased from 1595.22 to $1623.21 \mathrm{~cm}^{-1}$. The peak corresponding to asymmetric tensile vibrations of the group ( $\mathrm{C}-\mathrm{O}),(\mathrm{C}-\mathrm{N})$, and $(\mathrm{S}=0)$ has been transferred from 1143.96 to $1135.77 \mathrm{~cm}^{-1}$. The peak $(\mathrm{C}-\mathrm{H})$ has increased from 779.35 to $907.19 \mathrm{~cm}^{-1}$. The peak of aromatic rings has increased from 676.52 to $705.94 \mathrm{~cm}^{-1}$ [42].

All these changes and the increase of vibrations, and new peaks indicate the formation of a complex by Echium amoenum Fisch- 8Me (part of stem and leaf, wastes) extract and iron ions on the surface of St37 steel in $3.5 \mathrm{wt} \% \mathrm{NaCl}$. It also indicates an increase in the grafts' strength and more absorption of Echium amoenum Fisch- 8Me (part of stem and leaf, wastes) extract on the surface. As a result, the Echium amoenum Fisch- 8Me (part of stem and leaf, wastes) extract contains $\mathrm{S}, \mathrm{O}$, and $\mathrm{N}$ atoms in its functional groups and aromatic rings, and according to the general properties of organic inhibitors, can form a protective coating on the surface of st37 steel. Therefore, it can be said that the combination of several parts of the plant itself, such as part of the stem and leaf (wastes), Echium amoenum Fisch- 8Me has a significant effect on increasing the inhibitory efficiency of the extract and the most beneficial and effective compounds in inhibition have been taken. So the extract acts as a green inhibitor and prevents corrosion of St37 steel by creating a protective layer [45].

\section{SEM (Scanning Electron Microscopy)}

Scanning electron microscopy images with magnification of 200 (After 1.5 years from inhibitor fabrication) from the surface of st37 steel sample immersed in a corrosive medium of $3.5 \mathrm{wt} \% \mathrm{NaCl}$ after 24 hours without inhibitor and in the presence of a concentration of $100 \mathrm{ppm}$ from Echium amoenum Fisch- $8 \mathrm{Me}$ (part of stem and leaf, wastes) extract is shown in Figs 6-a and 6-b, respectively.

Scanning electron microscopy images of Figs 6-a and 6-b with magnification of 500 are shown in Figs 6c and 6-d, respectively. 
SEM images with magnifications of 200 and 500 in Fig. 6 shown after 24 hours of immersion in the corrosive medium of $3.5 \mathrm{wt} \% \mathrm{NaCl}$ without the presence of inhibitor and with the inhibitor. This test is 1.5 years after the inhibitor were made. This test shows that inhibitor retain their inhibitory properties after a long time, and the effect of the inhibitor on the surface morphology can be well seen. A more uniform surface in the presence of inhibitors can be seen in SEM images. Inhibitor protect from the surface of the steel sample by creating a protective film.[46-48].

\section{Conclusion}

- The potentiodynamic polarization evaluation revealed that Echium amoenum Fisch-8Me (part of stem and leaf, wastes) extract acts as a mixed type inhibitor in $3.5 \mathrm{wt} \% \mathrm{NaCl}$ medium.

- Electrochemical impedance spectroscopy results represented the formation of a protective layer on the surface of St37 steel in $3.5 \mathrm{wt} \% \mathrm{NaCl}$ solution containing Echium amoenum Fisch-8Me (part of stem and leaf, wastes) extract.

- FT-IR spectroscopic analysis confirms the formation of a complex between iron ions and active organic components of the extract on the steel surface in $3.5 \mathrm{wt} \% \mathrm{NaCl}$ corrosive environment. It can be said that the combination of several parts of the plant itself, such as part of the stem and leaf (wastes), Echium amoenum Fisch-8Me has a significant effect on increasing the inhibitory efficiency of the extract and the most beneficial and effective compounds in inhibition have been taken. So the extract acts as a green inhibitor and which eventually led to the formation of the most protective and barrier film on St37 steel.

- The microscopic image of the surface showed that by adding the Echium amoenum Fisch-8Me (part of stem and leaf, wastes) extract, a uniform surface was formed on the steel surface of St37, which indicates the formation of a protective film on the steel surface.

- According to the results, it can be said that the use of different parts of the plant could have a good effect on the construction of green inhibitors. This inhibitor at the concentration of $800 \mathrm{ppm}$ has been able to play an effective role as a green inhibitor.

\section{Abbreviations}

$\mathrm{NaCl}$ Sodium Chloride

EIS Electrochemical impedance spectroscopy

FT-IR Fourier transform infrared spectroscopy

SEM Scanning electron microscopy

EDS Energy-dispersive X-ray spectroscopy

Cr Chromium 
P Phosphorus

S Sulfur

N Nitrogen

O Oxygen

OCP Open circuit potential

$\mathrm{KBr}$ Potassium bromide

CPE Constant phase element

\section{Declarations}

\section{Acknowledgments}

The authors are grateful for support from the Shahid Bahonar University of Kerman. (bahare.ghanaati.2021@gmail.com)

\section{Statements and Declarations}

The authors declare that they have no known competing financial interests or personal relationships that could have appeared to influence the work reported in this paper.

\section{Data availability statements}

The datasets generated during and/or analysed during the current study are available from the corresponding author on reasonable request.

\section{References}

1. Sallau, A.A., Abubakar, A.B.: Inhibition effect of ethanolic extract of Ipomoea batatas peel on the corrosion of Mild steel in hydrochloric acid medium. Journal of Science and Mathematics Letters 8(1), 16-26 (2020)

2. Caiwen, et al.: Cleaning chromium pollution in aquatic environments by bioremediation, photocatalytic remediation, electrochemical remediation and coupled remediation systems. Environ. Chem. Lett. 18(3), 561-576 (2020)

3. Kołątaj, K., Krajczewski, J., Kudelski, A.: Plasmonic nanoparticles for environmental analysis. Environ. Chem. Lett. 18(3), 529-542 (2020)

4. Pasalari, H., et al.: Management of landfill leachate in Iran: valorization, characteristics, and environmental approaches. Environ. Chem. Lett. 17(1), 335-348 (2019) 
5. Popoola: and L.T., Organic green corrosion inhibitors (OGCls): a critical review. Corros. Rev. 37(2), 71-102 (2019)

6. Coetzee, J.J., Bansal, N., Chirwa, E.M.N.: Chromium in Environment, Its Toxic Effect from ChromiteMining and Ferrochrome Industries, and Its Possible Bioremediation. Exposure and Health 12(1), 51$62(2020)$

7. Zhou, Y., et al.: Health risk assessment of groundwater in Gaobeidian, north China: distribution, source, and chemical species of the main contaminants. Exposure and Health 12(3), 427-446 (2020)

8. Naseri, E., et al.: Inhibitive effect of Clopidogrel as a green corrosion inhibitor for mild steel; statistical modeling and quantum Monte Carlo simulation studies. J. Mol. Liq. 269, 193-202 (2018)

9. Chaubey, N., et al., Frontiers and advances in green and sustainable inhibitors for corrosion applications: A critical review. Journal of Molecular Liquids, 2020: p. 114385

10. Olajire, A.A.: Corrosion inhibition of offshore oil and gas production facilities using organic compound inhibitors-A review. J. Mol. Liq. 248, 775-808 (2017)

11. Dehghani, A., Bahlakeh, G., Ramezanzadeh, B.: A detailed electrochemical/theoretical exploration of the aqueous Chinese gooseberry fruit shell extract as a green and cheap corrosion inhibitor for mild steel in acidic solution. J. Mol. Liq. 282, 366-384 (2019)

12. Liu, Q., et al.: A novel green reinforcement corrosion inhibitor extracted from waste Platanus acerifolia leaves. Constr. Build. Mater. 260, 119695 (2020)

13. Verma, C., et al.: An overview on plant extracts as environmental sustainable and green corrosion inhibitors for metals and alloys in aggressive corrosive media. J. Mol. Liq. 266, 577-590 (2018)

14. Dehghani, A., et al.: Applying detailed molecular/atomic level simulation studies and electrochemical explorations of the green inhibiting molecules adsorption at the interface of the acid solution-steel substrate. J. Mol. Liq. 299, 112220 (2020)

15. Wang, Z., et al.: The Antioxidant and Enzyme Inhibitory Activity of Balsam Fir (Abies balsamea (L.) Mill.) Bark Solvent Extracts and Pyrolysis Oil. Waste Biomass Valoriz. 10(11), 3295-3306 (2019)

16. Bouraoui, M.M., et al.: Inhibition Efficiency of Cinnamon Oil as a Green Corrosion Inhibitor. Journal of Bio-and Tribo-Corrosion 5(1), 28 (2019)

17. Asfia, M.P., Rezaei, M., Bahlakeh, G.: Corrosion prevention of AISI 304 stainless steel in hydrochloric acid medium using garlic extract as a green corrosion inhibitor: electrochemical and theoretical studies. J. Mol. Liq. 315, 113679 (2020)

18. Elabbasy, H.M., Fouda, A.S.: Olive leaf as green corrosion inhibitor for C-steel in Sulfamic acid solution. Green Chem. Lett. Rev. 12(3), 332-342 (2019)

19. Pitchaipillai, M., et al.: Benevolent behavior of Kleinia grandiflora leaf extract as a green corrosion inhibitor for mild steel in sulfuric acid solution. International Journal of Minerals, Metallurgy, and Materials 21(11), 1083-1095 (2014) 
20. Raja, P.B., et al.: Inhibitive effect of Xylopia ferruginea extract on the corrosion of mild steel in $1 \mathrm{M} \mathrm{HCl}$ medium. International Journal of Minerals, Metallurgy, and Materials 18(4), 413 (2011)

21. Berrissoul, A., et al., Evaluation of Lavandula mairei extract as green inhibitor for mild steel corrosion in $1 \mathrm{M} \mathrm{HCl}$ solution. Experimental and theoretical approach. Journal of Molecular Liquids, 2020: p. 113493

22. El-Katori, et al.: Assessment of the Bassia muricata extract as a green corrosion inhibitor for aluminum in acidic solution. Green Chem. Lett. Rev. 12(1), 31-48 (2019)

23. Yüce, Ongun, A.: Corrosion Inhibition Behavior of Robinia pseudoacacia Leaves Extract as a EcoFriendly Inhibitor on Mild Steel in Acidic Media. Metals and Materials International (2019)

24. Chen, S., Zhu, B., Liang, X.: Corrosion Inhibition Performance of Coconut Leaf Extract as a Green Corrosion Inhibitor for X65 Steel in Hydrochloric Acid Solution. Int. J. Electrochem. Sci. 15, 1-15 (2020)

25. Mobin, M., Basik, M., Aslam, J.: Pineapple stem extract (Bromelain) as an environmental friendly novel corrosion inhibitor for low carbon steel in $1 \mathrm{M} \mathrm{HCl}$. Measurement 134, 595-605 (2019)

26. Rashid, et al.: Mathematical Modeling and Electrochemical Behavior for Corrosion Inhibition of Steel by Kiwi Juice Extract. Journal of Bio-and Tribo-Corrosion 6(1), 13 (2020)

27. Vorobyova, V., Skiba, M.: Peach Pomace Extract as Novel Cost-Effective and High-Performance Green Inhibitor for Mild Steel Corrosion in $\mathrm{NaCl}$ Solution: Experimental and Theoretical Research. Waste Biomass Valoriz. 12(8), 4623-4641 (2021)

28. Zhang, X., et al.: Evaluation of Idesia polycarpa Maxim fruits extract as a natural green corrosion inhibitor for copper in $0.5 \mathrm{M}$ sulfuric acid solution. J. Mol. Liq. 318, 114080 (2020)

29. Zuo, X., et al.: Research of Lilium brownii leaves extract as a commendable and green inhibitor for X70 steel corrosion in hydrochloric acid. J. Mol. Liq. 321, 114914 (2021)

30. Benabbouha, T., et al.: Red Algae Halopitys Incurvus extract as a green corrosion inhibitor of carbon steel in hydrochloric acid. Journal of Bio-and Tribo-Corrosion 4(3), 39 (2018)

31. Ferdosi Heragh, M., Tavakoli, H.: Electrochemical Properties of a New Green Corrosion Inhibitor Derived from Prosopis farcta for St37 Steel in $1 \mathrm{M}$ Hydrochloric Acid. Metals and Materials International (2019)

32. Abdallah, M., et al.: Natural nutmeg oil as a green corrosion inhibitor for carbon steel in $1.0 \mathrm{M} \mathrm{HCl}$ solution: Chemical, electrochemical, and computational methods. J. Mol. Liq. 323, 115036 (2021)

33. Santos, A., et al., Evaluation of palm kernel cake powder (Elaeis guineensis Jacq.) as corrosion inhibitor for carbon steel in acidic media. Metals and Materials International, 2020: p. 1-12

34. Bahlakeh, G., et al.: Novel cost-effective and high-performance green inhibitor based on aqueous Peganum harmala seed extract for mild steel corrosion in $\mathrm{HCl}$ solution: detailed experimental and electronic/atomic level computational explorations. J. Mol. Liq. 283, 174-195 (2019)

35. Galo, G.T., et al., Evaluation of purple onion (Allium Cepa L.) extract as a natural corrosion inhibitor for carbon steel in acidic media. Metals and Materials International, 2020: p. 1-12 
36. Hamrahi, B., et al.: Evaluation of Henna Extract Performance on Corrosion Inhibition of API 5L Steel in H 2 S-Containing Medium and DFT Quantum Computing of Its Constituents, pp. 1-14. Metals and Materials International (2020)

37. Zeng, X., et al.: Three imidazole ionic liquids as green and eco-friendly corrosion inhibitors for mild steel in sulfuric acid medium. J. Mol. Liq. 324, 115063 (2021)

38. Aslam, R., et al.: Ionic liquids derived from a-amino acid ester salts as potent green corrosion inhibitors for mild steel in 1M HCl. J. Mol. Liq. 318, 113982 (2020)

39. Guo, L., et al.: Locust Bean Gum as a green and novel corrosion inhibitor for Q235 steel in $0.5 \mathrm{M}$ H2SO4 medium. J. Mol. Liq. 310, 113239 (2020)

40. Haddadi, S.A., et al.: A detailed atomic level computational and electrochemical exploration of the Juglans regia green fruit shell extract as a sustainable and highly efficient green corrosion inhibitor for mild steel in 3.5 wt\% $\mathrm{NaCl}$ solution. J. Mol. Liq. 284, 682-699 (2019)

41. Jmiai, A., et al.: A new trend in corrosion protection of copper in acidic medium by using Jujube shell extract as an effective green and environmentally safe corrosion inhibitor: Experimental, quantum chemistry approach and Monte Carlo simulation study. J. Mol. Liq. 322, 114509 (2021)

42. Parthipan, P., et al.: Neem extract as a green inhibitor for microbiologically influenced corrosion of carbon steel API 5LX in a hypersaline environments. J. Mol. Liq. 240, 121-127 (2017)

43. Odewunmi, N., Umoren, S., Gasem, Z.: Watermelon waste products as green corrosion inhibitors for mild steel in $\mathrm{HCl}$ solution. Journal of Environmental Chemical Engineering 3(1), 286-296 (2015)

44. Saxena, A., et al.: Use of Saraca ashoka extract as green corrosion inhibitor for mild steel in $0.5 \mathrm{M}$ H2SO4. J. Mol. Liq. 258, 89-97 (2018)

45. Ramezanzadeh, M., et al., Highly effective inhibition of mild steel corrosion in 3.5\% $\mathrm{NaCl}$ solution by green Nettle leaves extract and synergistic effect of eco-friendly cerium nitrate additive: Experimental, MD simulation and QM investigations. Journal of Molecular Liquids, 2017

46. Raja, P.B., Sethuraman, M.G.: Inhibitive effect of black pepper extract on the sulphuric acid corrosion of mild steel. Materials letters 62(17-18), 2977-2979 (2008)

47. Rubaye, A., et al.: Cheery sticks plant extract as a green corrosion inhibitor complemented with LCEIS/MS spectroscopy. Int. J. Electrochem. Sci. 10(10), 8200-8209 (2015)

48. Oukhrib, R., et al.: Ziziphus lotus as green inhibitor of copper corrosion in natural sea water. Portugaliae Electrochimica Acta 35(4), 187-200 (2017)

\section{Figures}




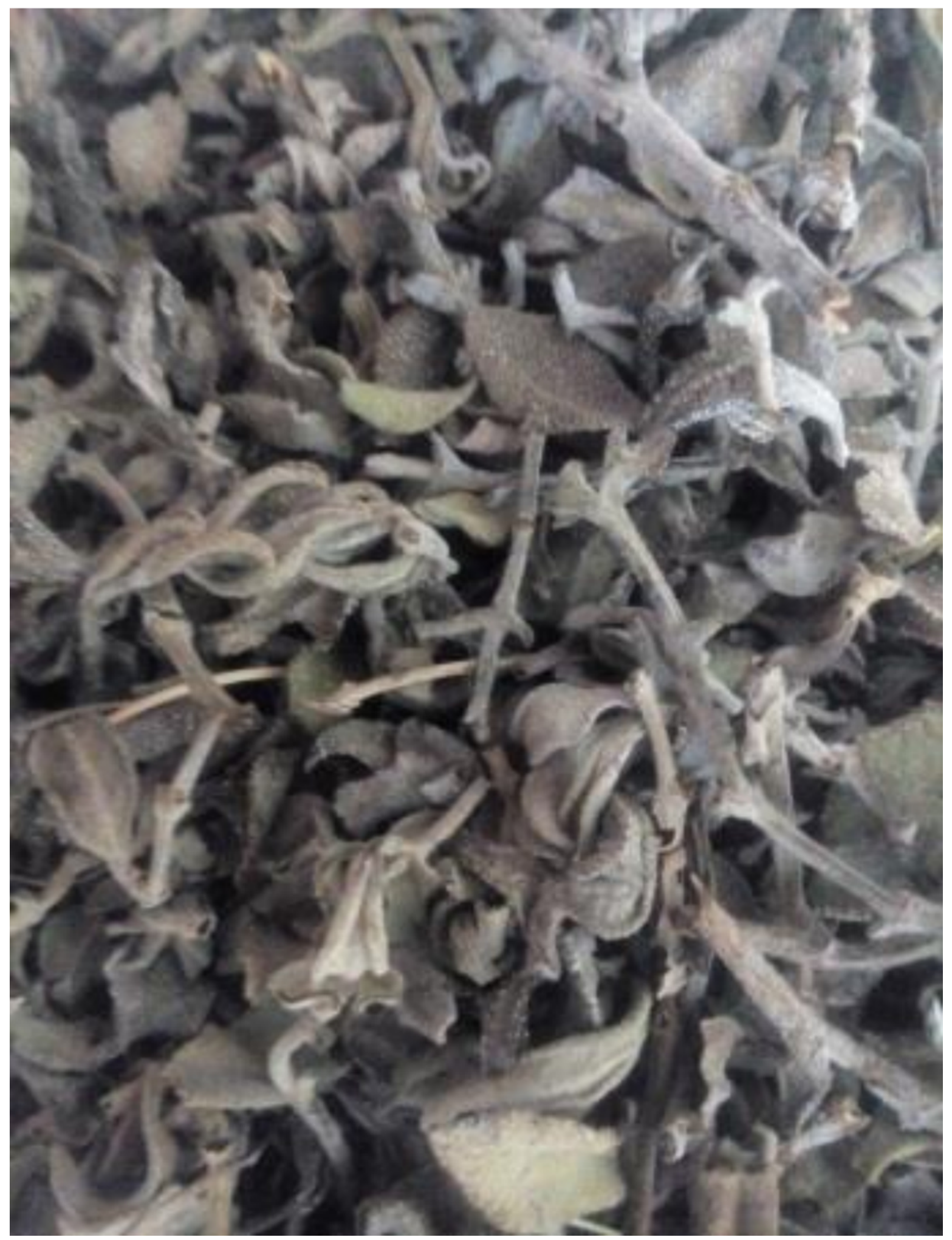

Figure 1

Image of Echium amoenum Fisch-8Me (part of stem and leaf, wastes), (dried) 


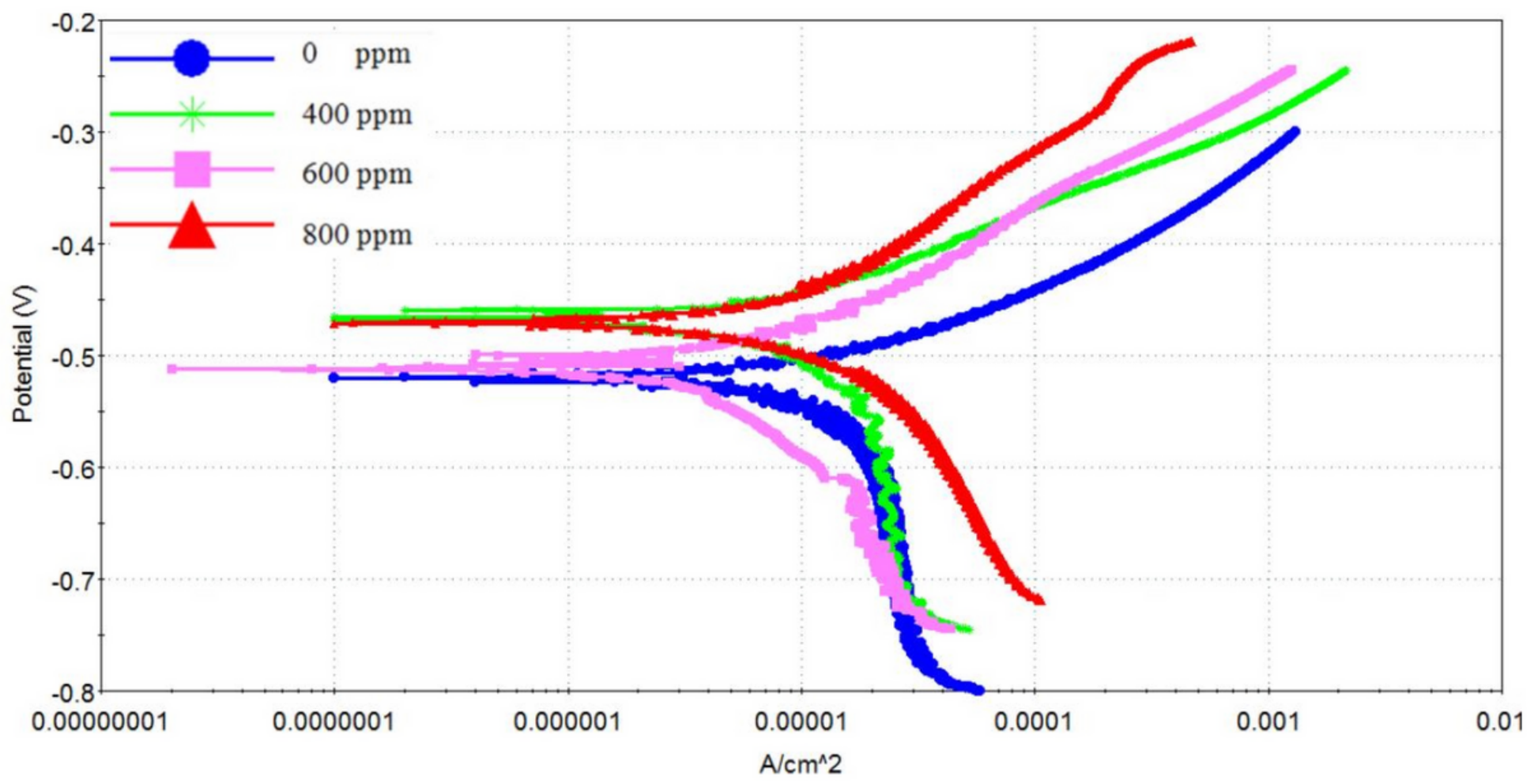

Figure 2

Polarization curves due to corrosion of St37 steel in $3.5 \mathrm{wt} \% \mathrm{NaCl}$ solution and containing Echium amoenum Fisch- 8Me (part of stem and leaf, wastes) extract with different concentrations 

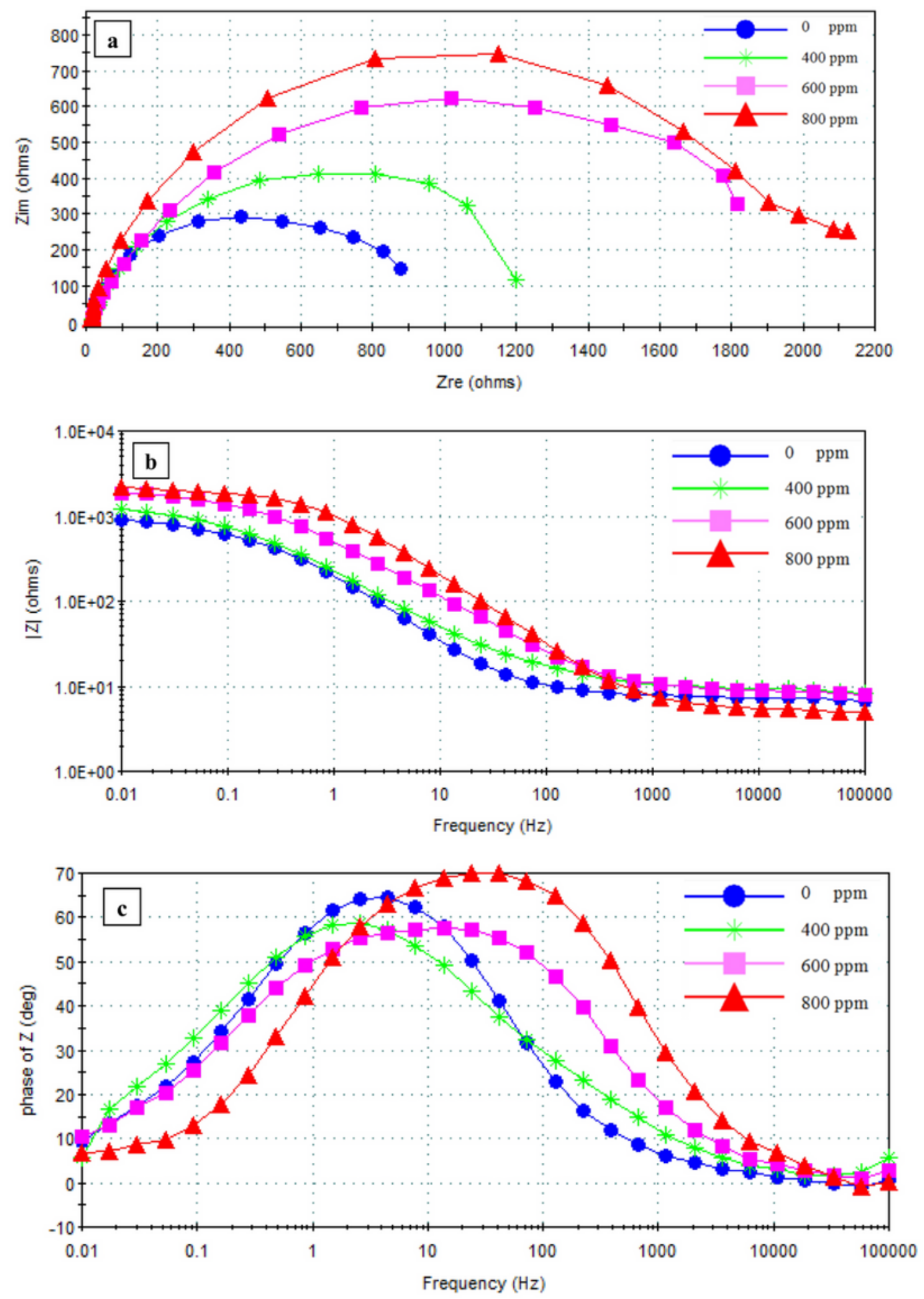

\section{Figure 3}

a) Nyquist curves, b) Bode curves, and c) Bode Phase curves of St37 steel in $3.5 \mathrm{wt} \% \mathrm{NaCl}$ solution containing Echium amoenum Fisch- $8 \mathrm{Me}$ (part of stem and leaf, wastes) extract with different concentrations of $0,400,600,800 \mathrm{ppm}$ 


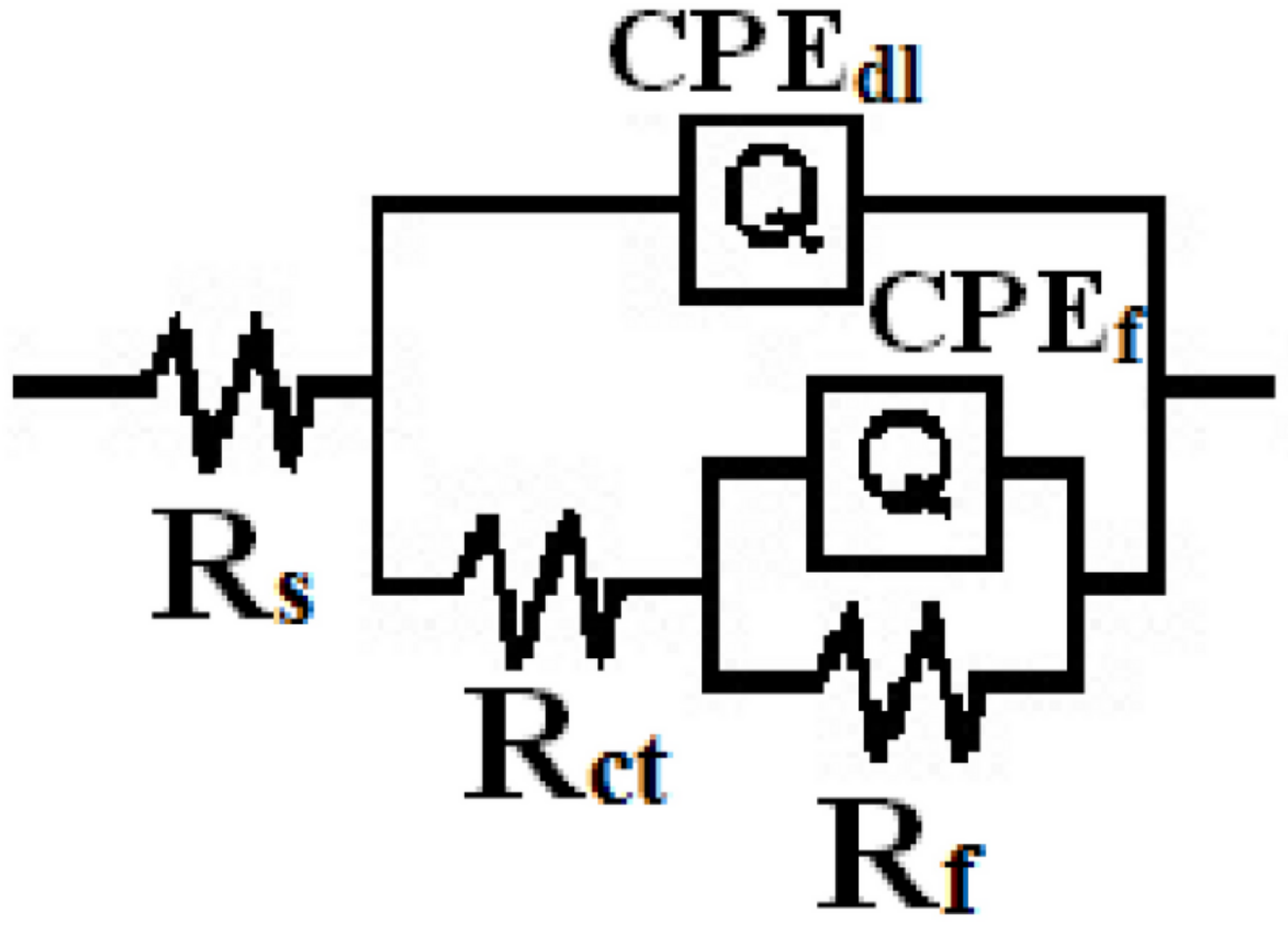

Figure 4

Equivalent circuit of St37 steel in $3.5 \mathrm{wt} \% \mathrm{NaCl}$ solution containing Echium amoenum Fisch- $8 \mathrm{Me}$ (part of stem and leaf, wastes) extract 

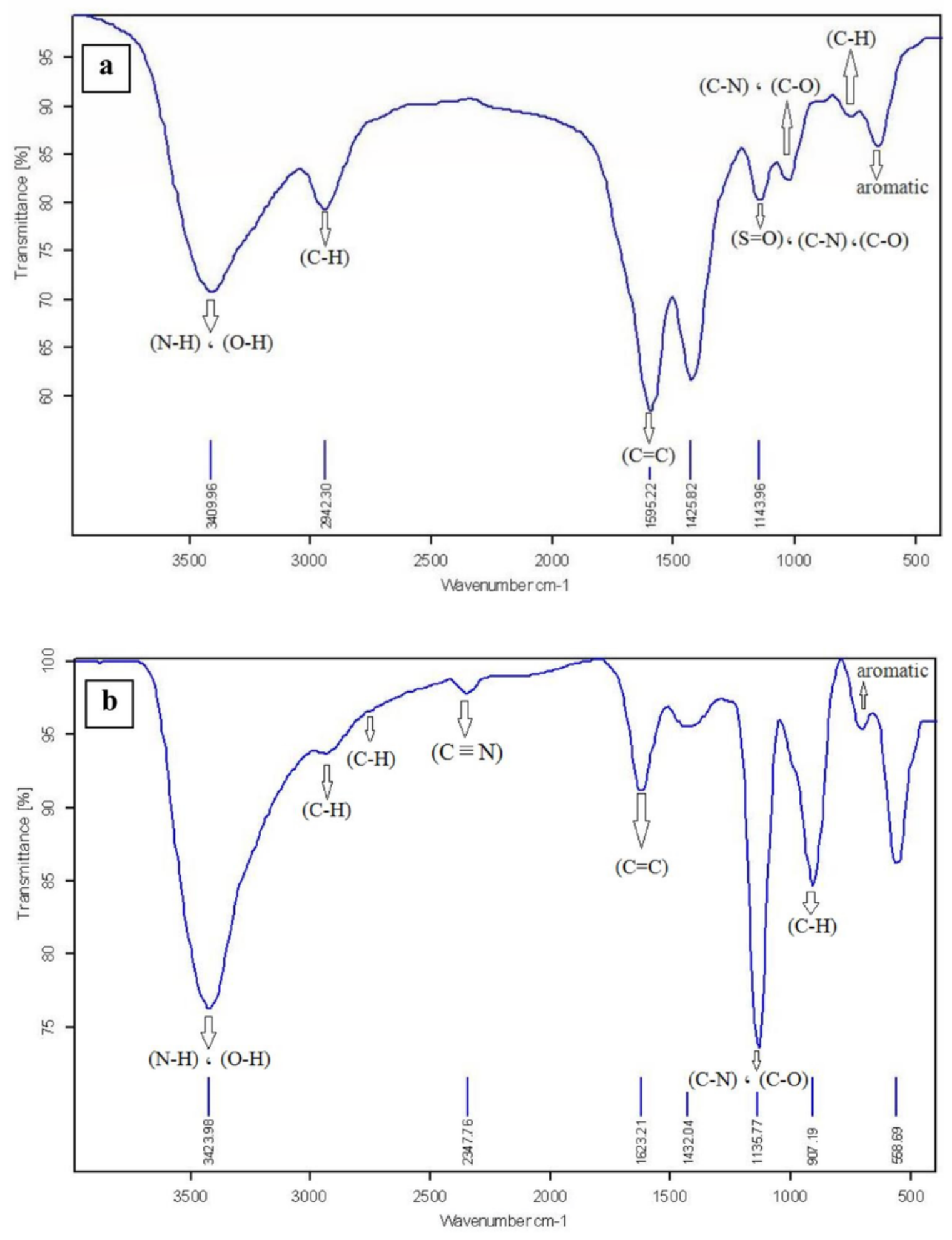

Figure 5

FT-IR spectrum a) Echium amoenum Fisch- 8Me (part of stem and leaf, wastes) extract powder and b) Surface film of steel sample St37 immersed in $3.5 \mathrm{wt} \% \mathrm{NaCl}$ solution containing one gr/l of Echium amoenum Fisch- $8 \mathrm{Me}$ (part of stem and leaf, wastes) extract for 24 hours 


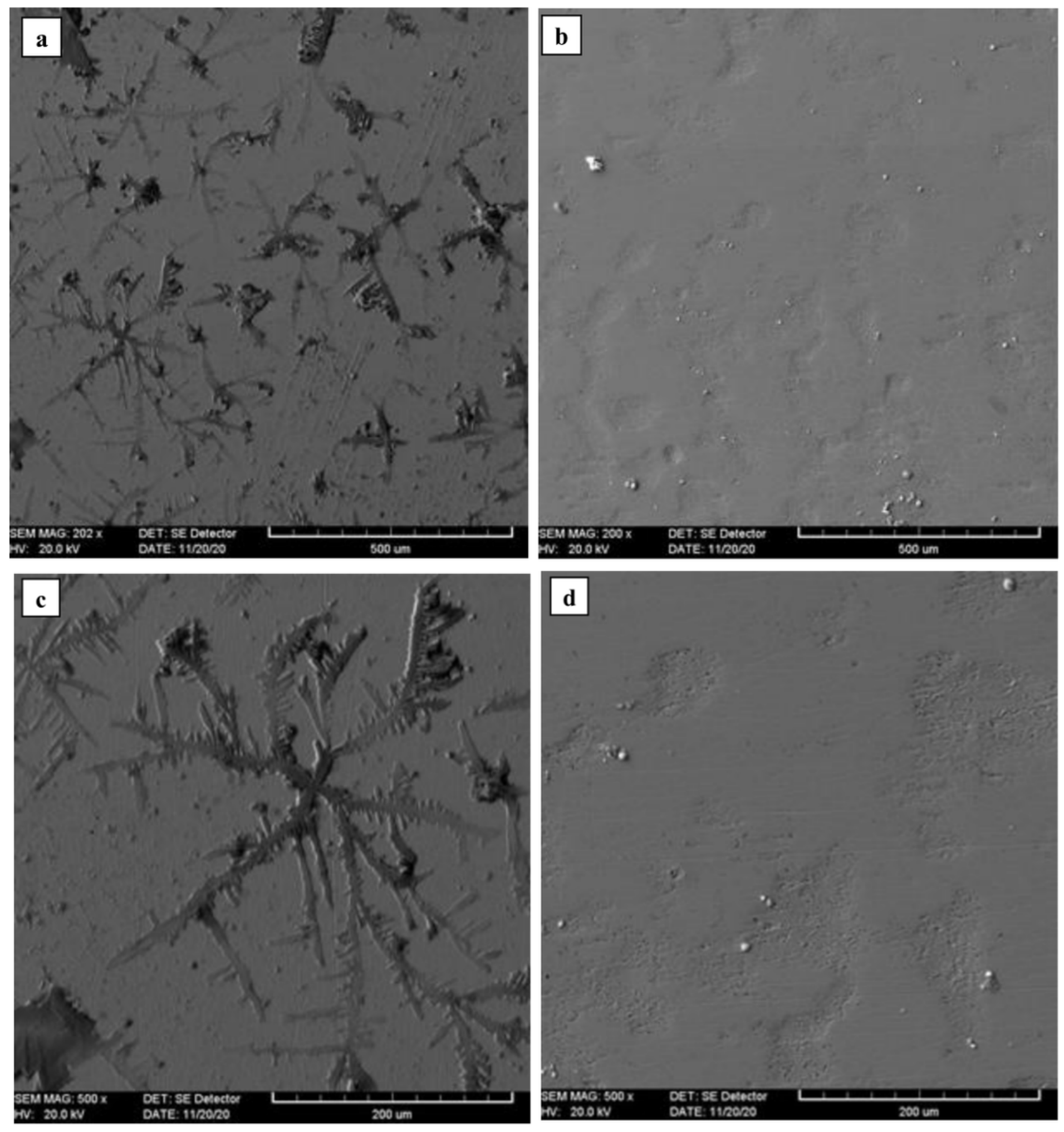

\section{Figure 6}

SEM images with the magnification of 200 from the surface of st37 steel sample immersed in a corrosive medium of $3.5 \mathrm{wt} \% \mathrm{NaCl}$ a) No extract (without the presence of inhibitor), b) Containing Echium amoenum Fisch- 8Me (part of stem and leaf, wastes) extract with a concentration of 100 ppm for 24 hours, c) Fig a with the magnification of 500 and d) Fig b with the magnification of 500 


\section{Supplementary Files}

This is a list of supplementary files associated with this preprint. Click to download.

- Graphicalabstract.jpg 